Available online on 15.09.2018 at http://jddtonline.info Journal of Drug Delivery and Therapeutics

Open Access to Pharmaceutical and Medical Research

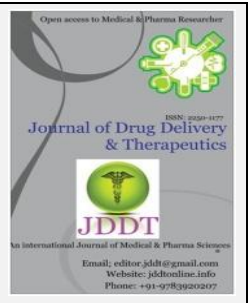

Open $\odot$ Access

Review Article

\title{
REVIEW ON POTENT ANTI-DIABETIC PLANTS OR HERBS FROM TRADITIONAL MEDICINE
}

\author{
Shilpa S. Kolhe*, Punit R. Rachh \\ Bhagwant University, Ajmer Rajastan India
}

\begin{abstract}
This review focuses on Indian Herbal drugs and plants used in the treatment of diabetes, especially in India. Diabetes is an important human ailment afflicting many from various walks of life in different countries. diabetes is one of the major causes of death and disability in the world. Natural products from medicinal plants, either as pure compounds or as standardized extracts, provide unlimited opportunities for new drug leads because of the unmatched availability of chemical diversity. Due to an increasing demand for chemical diversity in screening programs, seeking therapeutic drugs from natural products, interest particularly in edible plants has grown throughout the world. Botanicals and herbal preparations for medicinal usage contain various types of bioactive compounds. Phytochemicals identified from medicinal plants present an exciting opportunity for the development of new types of therapeutics for diabetes mellitus. Most prevalent among phytochemical groups are the alkaloids, glycosides, polysaccharides, and phenolics such as flavonoids, terpenoids and steroids. These include, Allium sativum, Eugenia jambolana, Momordica charantia Ocimum sanctum, Phyllanthus amarus, Pterocarpus marsupium, Tinospora cordifolia, Trigonella foenum graecum and Withania somnifera.
\end{abstract}

Keywords: Phytochemicals, diabetes, standardized extracts, bioactive compounds.

Article Info: Received 12 July, 2018; Review Completed 08 Aug 2018; Accepted 11 Aug 2018; Available online 15 Sep 2018

\section{Cite this article as:}

Kolhe SS, Rachh PR, Review on potent anti-diabetic plants or herbs from traditional medicine, Journal of Drug Delivery and Therapeutics. 2018; 8(5):92-98 DOI: http://dx.doi.org/10.22270/jddt.v8i5.1856

*Address for Correspondence: Shilpa S. Kolhe, Bhagwant University, Ajmer Rajastan India

\section{INTRODUCTION}

"In the light of this knowledge,

There is no substance in this world

May not be used as medicine in

This or that manner,

And for this or that purpose"

Nature always stands as a golden mark to exemplify the outstanding phenomenon of symbiosis the plant are in dispersible to man for his life .a large portion of the Indian population even today depends on the Indian system of medicine-Ayurveda "an ancient science of life, 1

According to the World Health Organization (WHO), more than $80 \%$ of the world's population relies on traditional medicine for their primary healthcare needs.
The use of herbal medicines in Asia represents a long history of human interactions with the environment. ${ }^{2}$

These plants have no side effects and many existing medicines are derived from the plants. The purpose of this systematic review is to study diabetes and to summarize the available treatments for this disease, focusing especially on herbal medicine. ${ }^{3}$

Diabetes is a lifelong (chronic) disease and is a group of metabolic disorders characterized by high levels of sugar in blood (hyperglycemia) ${ }^{4}$. More than 230 million people worldwide are affected, and it is expected to reach 350 million by 2025 . Globally the affected people are unaware of the disease and only half receive adequate treatment ${ }^{5}$. It is caused due to deficiency of insulin or resistance to insulin or both. Insulin is secreted by $\beta$-cells of pancreas to control blood sugar levels 4. Blurry visions, excess thirst, fatigue, frequent 
urination, hunger, weight loss are some of the symptoms commonly seen in diabetic patients ${ }^{6}$.

\section{Types}

Diabetes results in the impairment of the body's ability to use food because either the pancreas does not make insulin or the body cannot use insulin properly. Hypoglycemia (low blood glucose) is most commonly seen in diabetic patients, when the body gets too much insulin, too little food, a delayed meal, or more than the usual amount of exercise. When the body gets too little insulin, too much food, or too little exercise, it results in hyperglycemia (high blood glucose) ${ }^{7,8}$. Stress may contribute to hyperglycemia. Hyperglycemic state (diabetes mellitus) arises when the blood glucose (sugar) levels are higher than $180 \mathrm{mg} / \mathrm{dl}(10 \mathrm{mmol} / \mathrm{l})^{9}$.

Diabetes is of mainly three types. They are type-1 diabetes (T1D), type-2 diabetes (T2D) and gestational diabetes mellitus. T1D, also called as the insulindependent diabetes mellitus (IDDM), manifests due to the autoimmune damage of the $\beta$-cells which then leads to the suppression or cessation of insulin production. T1D is also called the "juvenile diabetes". T2D, also called as the adult-onset diabetes or non-insulindependent diabetes mellitus (NIDDM) among humans is caused by either low levels or absence of insulin or insulin resistance (IR) 9. Gestational diabetes mellitus (GDM) is defined as glucose intolerance of varying degrees, which appears, or is first diagnosed, during pregnancy and may or may not persist after delivery 10,11

Potential Anti diabetic medicinal plant reported from India: Antidiabetic principle from traditional medicinal plants. Many compounds isolated from plant sources have been reported to show antidiabetic activity. The table summarizes some recent information in the field of antidiabetic phytochemicals Many kinds of natural products, such as terpenoids, alkaloids, flavonoids, phenolics, and some others, have shown antidiabetic potential. Particularly, schulzeines A, B, and C, radicamines $\mathrm{A}$ and $\mathrm{B}$, 2,5-imino-1,2,5-trideoxy-Lglucitol, betahomofuconojirimycin, myrciacitrin IV, dehydrotrametenolic acid, corosolic acid (Glucosol), 4 (alpha-rhamnopyranosyl) ellagic acid, and 1,2,3,4,6pentagalloylglucose have shown significant antidiabetic activities.

\section{Medicinal plants used in diabetes}

1. Annona squamosa Linn - Annonaceae

2. Argyreia speciosa (Linn. f.)- Convulaceae

3. Andrographis paniculata (Burm.f.) - Acanthaceae

4. Aegle marmelos (L.) - Corrêa Rutaceae

5. Azardirachta indica A.Juss., - Meliaceae

6. Acacia catechu (Willd.)- Leguminosae

7. Aerva lanata (L.) Juss. - Amarantaceae

8. Allium cepa Linn- Amaryllidaceae

9. Allium sativum Linn - Amaryllidaceae

10. Aloe vera (L.) Burm.f.- Xanthorrhoeaceae

11. Alpinia calcarata Roxb., - Zingiberaceae

12. Benincasa hispida (Thunb) - Cucurbitaceae

13. Barleria prionitis Linn - Acanthaceae

14. Crateva nurvula (Lour.) - Capparidaceae
15. Cocculus hirsutus DC. -Menispermaceae

16. Capsicum annum Linn- Solanaceae

17. Cedrus deodara Roxb -Coniferae

18. Coccinia indica W\&A -Cucurbitaceae

19. Cassia auriculata (L.) Roxb. --Caesalpiniaceae

20. Cassia glauca Linn- Caesalpinaceae

21. Capparis sepiaria Linn-Capparidaceae

22. Cajanus cajan Adans. -Fabaceae

23. Coccinia indica (L.) Voigt -Cucurbitaceae

24. Caesalpinia bonducella (L.) Roxb.- Caesalpiniaceae

25. Emblica officinalis S Gaertn -Phyllanthaceae

26. Eugenia jambolana Lam -Myrtaceae

27. Ficus bengalenesis Linn -Moraceae

28. Ficus gibosa BI -Moraceae

29. Ficus glomerata Roxb -Moraceae

30. Gymnema sylvestre R.Br -Asclepiadaceae

31. Helicteres isora Linn -Sterculiaceae

32. Holostemma annulare K.Schum -Asclepiadaceae

33. Holostemma ada Kodien-Asclepiadaceae

34. Helicteres isora Linn-Sterculiaceae

35. Hemidesmus indicus (L.) R.Br. -Apocynaceae

36. Jatropha curcas Linn -Euphorbiaceae

37. Mimosa pudica Linn -Fabaceae

38. Momordica charanti Linn Cucurbitaceae

39. Ocimum sanctum Linn- Lamiaceae

40. Plumbago rosea Linn- Plumbaginaceae

41. Pterocarpus marsupium Roxburgh -Fabaceae

42. Rubia cordifolia Linn -Rubiaceae

43. Rosa canina Linn -Rosaceae

44. Salacia fruticosa Linn -Celastraceae

45. Salacia oblonga Wall -Hippocrateaceae

46. Saraca indica Linn- Leguminosae

47. Stroblanthus hyneanus Nees -Acanthaceae

48. Swertia chirayita Linn -Gentianaceae

49. Syzigium cumini (L.) Skeels. -Myrtaceae

50. Trigonella foenum graecum Linn -Fabaceae

51. Trichosanthes dioica Roxb. -Cucurbitaceae

52. Tinospora cordifolia Miers -Menispermaceae

53. Tragia involucrate Linn- Euphorbiaceae

54. Tribulus terrestris Linn -Zygophyllaceae

55. Vinca rosea (L.) G.Don -Apocynaceae

Onion (Allium сера); Alliaceae and garlic (Allium sativum L.) ${ }^{12}$

Oral administration of onion (A. cepa L.) and garlic ( $A$. sativum $L$.) to alloxan-induced diabetic rats for 30 days ameliorated hyperglycemia, reversed weight loss and depletion of liver glycogen. The anti-diabetic bioactive principles of $A$. серa $L$. and A. sativum $L$. were Smethylcysteinesulfoxide (SMCS) and Sallylcysteinesulfoxide (SACS) respectively. The studies showed that SMCS and SACS exerted their anti-diabetic properties by stimulating insulin secretion as well as compete with insulin for insulin inactivating sites in the liver. Specifically, SACS inhibited gluconeogenesis in the liver. In addition, SACS from A. sativum $\mathrm{L}$ impeded lipid peroxidation due to its antioxidant and secretagogue actions. The capacities of A. cepa $L$. and $A$. sativum $L$. to alleviate DM in the experimental rats were comparable with diabetic rats treated with glibenclamide and insulin. The study also noted that SMCS and SACS caused significant increase in the biosynthesis of cholesterol from acetate in the liver, which was an 
indication of low capacities of allium products to protect the rats against risk factors associated with DM.

Aloe vera (Aloe barbedensis); Aspholedeceae ${ }^{13}$

A $1.0 \mu \mathrm{g}$ of five phytosterols- lophenol, 24-methyllophenol, 24-ethyl-lophenol, cycloartanol, and 24methylene-cycloartanol from A. vera exhibited comparable capacities to lower blood glucose levels in Type II diabetic BKS.Cg-m+/+Lepr ${ }^{\mathrm{d} / \mathrm{J}}(d b / d b)$ mice following 28 day treatment. The five phytosterols caused significant decrease in blood HbA1c levels by $15-18 \%$. Additionally, severe diabetic mice treated with the five phytosterols did not suffer weight loss because of rapid excretion of glucose in the urine. The findings suggested that phytosterols derived from $A$. vera gel have a long-term blood glucose lowering effect, which could be applied as agents of glycemic control in Type 2 DM. Studies showed thatphytosterols stimulate the biosynthesis and/or release of insulin as well as alter the activity of carbohydrate metabolizing enzymes.

Catharanthus roseus [L.] G. Don; Apocynaceae ${ }^{14}$

The Madagascar periwinkle (C. roseus), is a traditional remedy and was marketed in England as 'Vinculin' for the treatment of DM. Earlier studies showed that leaf aqueous extracts of $C$. roseus administered orally to rabbits and dogs caused hypoglycemic response. Similar studies using variety of laboratory animals and limited clinical trials gave negative or at best equivocal results. Alkaloids, notably, catharanthine 17 , leurosine ${ }^{18}$, lochnerine ${ }^{19}$, tetrahydroalstonine ${ }^{20}$, vindoline ${ }^{21}$, and vindolinine ${ }^{22}$ are the major anti-diabetic principles present in $C$. roseus. Specifically, studies showed that vincamine ${ }^{23}$ and (-)-eburnamonine ${ }^{24}$ caused extensive decrease in rat brain tissue glucose concentration, with concomitant increase in lactate and pyruvate concentrations as well as the lactate pyruvate ratio and increase in tissue ATP contents. In vitro studies showed that the quinoline derivatives, quinolate and 3mercaptopicolinate, inhibited hepatic gluconeogenesis from lactate or alanine by inhibiting muscle cytosolic/ mitochondrial phosphoenolpyruvate carboxykinase and cytosolic aspartate aminotransferase activities. Certainly the active alkaloids analogs of $C$. roseus exhibited oral hypoglycemic activity of one third capacities when compared with tolbutamide.

Oral administration of dichloromethane:methanol (1:1) leaf and twig extracts of C. roseus at dose $=500 \mathrm{mg} / \mathrm{kg}$ to streptozotocin (STZ)-induced diabetic rats for 7 and 15 days gave 48.6 and $57.6 \%$ hypoglycemic activity, respectively. The same dose for 30 days exhibited protective effect against STZ challenge. The antidiabetic action of $C$. roseus was as a result of inhibition of hepatic glycogen synthase, glucose 6-phosphatedehydrogenase, succinate dehydrogenase and malate dehydrogenase activities coupled with increased mobilization of glucose following treatment of the experimental rats. Similarly, the same dose of $C$. roseus extracts ameliorated oxidative stress as exemplified by lower levels of 2-thiobarbituric acid reactive substances (TBARS) in diabetic rats following treatment.

Cinnamomum cassie (Chinese cinnamon); Lauraceae ${ }^{15}$
Cinnamon methylhydroxychalcone polymer (MHCP) from cinnamon functions as a mimetic for insulin in 3T3-L1 adipocytes. Therefore, MHCP may be useful in the treatment of Type II DM and in the study of the pathways leading to glucose utilization in peripheral cells.

Coccinia indica; cucurbibaceae ${ }^{16,17}$

Orally administered pectin materials isolated from fruit extracts of $C$. indica at dose $=200 \mathrm{mg} / 100 \mathrm{~g}$ body weight/day caused hypoglycemia in normal rats. The study noted that pectin materials caused significant reduction in blood glucose and an increase in the liver glycogen as a result of increase in hepatic glycogen synthetase activity and corresponding reduction in phosphorylase activity. Hypoglycemic effect of ethanolic extract of $C$. indica is partly due to the repression of the key gluconeogenic enzyme (glucose-6phosphatase), but did not affect alanine aminotransferase and aspartate amino transferase activities, in starved male rats.

\section{Fiscus bengalensis; Moraceae ${ }^{18}$}

Leucopelargonidin-3-0-alpha-L rhamnoside from dimethoxy ether extract of Indian Banyan tree $F$. bengalensis Linn bark at a medium effective dose $=100$ $\mathrm{mg} / \mathrm{kg}$ caused hypoglycemia and increased blood insulin levels in normal and moderately alloxan-induced diabetic dogs following two hours oral administration. The bioactive glycoside stimulated insulin secretion in the experimental animals. Furthermore, acute (doses = $0.2-1.8 \mathrm{~g} / \mathrm{kg}$ ) administration to mice and chronic (doses $=100,250$ and $500 \mathrm{mg} / \mathrm{kg}$ ) daily administration to rats for a period of one month respectively did not elicit toxic effects even at the high dose of $1.8 \mathrm{~g} / \mathrm{kg}$ in experimental animals.

\section{Gymmema slyvestre (Gurnar); Asclepiadaceae ${ }^{18}$}

G. sylvestre extracts at various doses caused decreased blood sugar level in STZ-induced diabetic rat models, which was comparable with the standard anti-diabetic drug-tolbutamide. Also, human experiments showed that GS4 (dose $=400 \mathrm{mg} /$ day), a water-soluble extract from leaves of $G$. sylvestre, administered to patients suffering from insulindependent diabetes mellitus (IDDM) and placed on insulin therapy, caused the normalization of their serum lipid profiles, whereas insulin requirements together with fasting blood glucose and glycosylated haemoglobin $\left(\mathrm{HbA}_{\mathrm{lc}}\right)$ and other glycosylated plasma protein levels remained higher than that of the control subjects. Nevertheless, GS4 therapy appears to enhance endogenous insulin biosynthesis, possibly by regeneration/revitalization of the residual $\beta$-cells of IDDM individuals.

\section{Ginseng (Panax ginseng); Araliaceae and Fenugreek (Trigonella foenum-graecum L.) ${ }^{19}$}

In vivo experiments using STZ-induced diabetic rats chronically administered with food mixed with steroid saponins from the seeds of fenugreek ( $T$. foenumgraecum $\mathrm{L})($ dose $=12.5 \mathrm{mg} / 300 \mathrm{~g}$ body weight per day) showed significantly increase in food intake as well as the motivation to eat in normal rats. it also stabilized the 
food consumption in diabetic rats, which resulted in a progressive weight gain in these animals, in contrast to untreated diabetic controls. Aerobic exercise in combination with ginsenosides from $P$. ginseng promote lower serum lipid, regulate lipid metabolism, promote anti-oxidation, and enhance immune activity.

\section{Momordica cymbalaria (Bitter Melon); Cucurbiteae ${ }^{20}$}

Oral and intra-peritoneal administration of aqueous fruit extracts of $M$. charantia to normal rats lowered the glycemic response without altering the insulin response. Also, aqueous extract and the residue after alkaline chloroform extraction reduced hyperglycemia in diabetic mice after 1 hour. The recovered plant matters by acid water wash of the chloroform extract following alkaline water wash engendered a slower hypoglycemic effect. These findings suggested that orally administered $M$. charantia extracts lower glucose concentrations independently of intestinal glucose absorption and involved an extra-pancreatic effect.

In another study, M. cymbalaria fruit powder caused reduction in blood sugar concentrations in alloxaninduced diabetic rats following 15 days treatment. Elevated serum cholesterol and triglycerides levels were lowered with significant improvement in hepatic glycogen level in treated diabetic rats. The study showed the anti-diabetic and hypolipidemic properties of $M$. cymbalaria fruit powder.

\section{Muurrayi komingii (Cury leaf); Rutaceae ${ }^{20}$}

A single oral administration of aqueous leaf extracts of M. koenigii $($ doses $=200,300$ and $400 \mathrm{mg} / \mathrm{kg}$ ) lowered blood glucose level in normal and alloxan-induced diabetic rabbits. The reduction on blood glucose levels in normal and mild diabetic rabbits corresponded to $14.68 \%$ and $27.96 \%$ following 4 hours of oral administration of $300 \mathrm{mg} / \mathrm{kg}$ of the leaf extract. Likewise, $300 \mathrm{mg} / \mathrm{kg}$ of the leaf extract caused a marked improvement in glucose tolerance by $46.25 \%$ in subdiabetic and $38.5 \%$ in mild diabetic rabbits at 2 hours post prandial test. The study suggested that the aqueous leaf extracts of $M$. koenigii may be prescribed as adjunct to dietary therapy and treatment of DM. Aegle marmelos possess anti-diabetic and hypolipidemic effects in diabetic rats.

\section{Ocimum sanctum (Holy basil); Lamiaceae ${ }^{21}$}

Alcoholic leaf extract $O$. sanctum ameliorates hyperglycemia in normal-glucose fed hyperglycemic and streptozotocin-induced diabetic rats by potentiating the action of exogenous insulin in the rats. The antidiabetic action of alcoholic leaf extract $O$. sanctum was comparable with that of the standard anti-diabetic drugtolbutamide.

Allium cepa, Allium sativum, Aloe vera, Cajanus cajan, Coccinia indica, Caesalpinia bonducella, Ficus bengalenesis, Gymnema sylvestre, Momordica charantia, Ocimum sanctum, Pterocarpus marsupium, Swertia chirayita, Syzigium cumini, Tinospora cordifolia and Trigonella foenum-graecum

All the above named plants stimulate insulin release from isolated pancreatic Islets cells by virtue of their phytochemical contents, especially the saponins and glycosides fractions.

\section{Polygala senega; Polygalaceae ${ }^{21}$}

The triterpenoid glycoside-Senegin-II and saponins are the main anti-diabetic components of $P$. senega (L.). Study showed that n-butanol extract of $P$. senega rhizomes $(\mathrm{SN})($ dose $=5.0 \mathrm{mg} / \mathrm{kg})$ caused reduction in the blood glucose of normal and KK-Ay mice following 4 hours intra-peritoneal administration. However, STZinduced diabetic mice did not experience significant change in the blood glucose following the administration of SN. The study proposed that the hypoglycemic effect of $\mathrm{SN}$ occurs without altering plasma insulin concentration.

\section{Syzigium cumini (Eugenia janbolaria); Mytaceae ${ }^{22}$}

At the dose levels of 200 and $400 \mathrm{mg} / \mathrm{kg}$, ethyl acetate and methanol extracts of S. cumini (Myrtaceae) seed exhibited significant antiinflammatory activity in carrageenan induced paw edema in Wistar rats. This anti-inflammatory activity of the plant extract could be of therapeutic benefit by ameliorating increased inflammatory response associated with DM.

\section{Trigonella foemum-graecum (Fenugreek) ${ }^{23}$}

T. foenum-graecum (Fenugreek) seeds fraction (dose $=$ $0.5 \mathrm{~g} / \mathrm{kg}$ body weight) significantly exerted glycemic control in normal, Type I or Type II diabetic rats. The soluble dietary fibre (SDF) fraction controlled elevation of blood glucose after oral ingestion of sucrose in normal and Type II diabetic rats. Intestinal disaccharides activity and glucose absorption were sufficiently suppressed, whereas gastrointestinal motility increased following treatment of the rats with SDF fraction. Daily oral administration of SDF to Type II diabetic rats for 28 days caused decreased serum glucose level but increased liver glycogen content with enhanced total antioxidant status. Serum insulin and insulin secretion were not affected by the SDF fraction. Overall, $T$. foenum-graecum seed extracts enhanced glucose transport in 3T3-L1 adipocytes as well as increased insulin sensitivity. Therefore, SDF fraction of $T$. foenum-graecum seeds exerted anti-diabetic effects through inhibition of carbohydrate digestion and absorption, and enhancement of peripheral insulin action.

Large classes of compounds are available from many plant sources. Natural products such as plant extracts, phytochemicals, and microbial metabolites are currently studied for their potential uses in the treatment and prevention of diabetes mellitus. A number of plant extracts and natural biomolecules have shown very promising effects indicating that the dietary intake of phytochemicals could be a promising strategy for diabetes prevention .

Polyphenolic compounds, especially flavonoids have been studied a lot with regard to their antidiabetic properties. Flavonoids are of plant origin and are known for their antioxidant, anti-inflammatory, and anticarcinogenic properties. Dietary intake of flavonoids may be an important alternative diabetes treatments and 
for the reduction of the risk of the disease. Therapies based on phytochemicals therefore constitute a novel pharmacological approach for treatment or an approach that would reinforce existing treatments.

\section{CONCLUSION}

From the above stud it was concluded that the most common disadvantage of using synthetic drugs is their serious side effects. This led to the use of medicines which have less/no side effects i.e., herbal medicines. The herbal medicines are considered to be better compatible with human body and are made from renewable resources of raw materials, easily available as well as cost effective. In this context, plants either wholly or a part of it or combination of its parts is used either directly or as a formulation. Various plants have been cited as examples.

\section{REFERENCES}

1. Saikat Chakraborty R, Biplab D. Challenges and Opportunities in the Advancement of Herbal Medicine: India's Position and Role in a Global Context. Journal of Herbal Medicine. 2011; 1:76-75

2. Http://Www.Indianmirror.Com/Ayurveda/Pleurisy.Html

3. Grover J.K., Yadav S., Vats V. Medicinal Plants Of India With Antidiabetic Potential. J. Ethnopharmacol. 2002; 81:81-100.

4. Ribeiro C, de Alencar Mota CS, Voltarelli FA, de Araújo MB, Botezelli JD, et al. Effects of Moderate Intensity Physical Training in Neonatal Alloxan- Administered Rats. J Diabetes Metab. 2010; 1:107.

5. da Silva SB, Costa JP, Pintado ME, Ferreira DC, Sarmento B. Antioxidants in the Prevention and Treatment of Diabetic Retinopathy - A Review. J Diabetes Metab. 2010; 1:111.

6. http://www.ncbi.nlm.nih.gov/pubmedhealth/PMH0002194/

7. Ragheb R, Medhat AM. Mechanisms of Fatty Acid-Induced Insulin Resistance in Muscle and Liver. J Diabetes Metab. 2011;2:127.

8. Mungrue K, Roper LA, Chung T. Assessment of Weight Loss in the Management of Patients with Type 2 Diabetes Mellitus in Primary Care in Trinidad. J Diabetes Metab. 2011; 2:120.

9. Alina S, Barbara R, Krzysztof G, Barbara G, Mare k G, et al. Elevation of sE-Selectin Levels from 2-24 Months Following Gestational Diabetesis Associated with Early Cardiometabolic Risk in Non-Diabetic Women. J Diabetes Metab. 2011; 2:138.

10. Kablan A, Saunders RA, Szkudlarek-Mikho M, Chin JB, Bosio RM, et al. Prieurianin Causes Weight Loss in DietInduced Obese Mice and Inhibits Adipogenesis in Cultured Preadipocytes. J Diabetes Metab. 2010; 1:101

11. Taloyan M, Saleh-Stattin N, Johansson SE, Agréus L, Wändell P. Differences in Cardiovascular Risk Factors in Swedes and Assyrians/Syrians with Type 2 Diabetes: Association with Lifestyle-Related Factors. J Diabetes Metab. 2010; 1:110.

12. Sheela CG, Kumud K, Augusti KT, Anti-diabetic effects of onion and garlic sulfoxide amino acids in rats. Planta Med 1995; 61:356-357.

13. Rajasekaran S, Sivagnanam K, Ravi K, Subramanian S, Hypoglycemic effect of Aloe vera gel on streptozotocininduced diabetes in experimental rats. J Med Food 2004; 7:6166.

14. Singh SN, Vats P, Suri S, Shyam R, Kumria MM, et al., Effect of an antidiabetic extract of Catharanthus roseus on enzymic activities in streptozotocin induced diabetic rats. J Ethnopharmacol 2001; 76:269-277

15. Jarvill-Taylor KJ, Anderson RA, Graves DJ, A hydroxychalcone derived from cinnamon functions as a mimetic for insulin in 3T3-L1 adipocytes. J Am Coll Nutr 2001; 20:327-336.

16. Hossain MZ, Shibib BA, Rahman R, Hypoglycemic effects of Coccinia indica: inhibition of key gluconeogenic enzyme, glucose-6-phosphatase. Indian J Exp Biol 1992; 30:418-420.

17. Kumar GP, Sudheesh S, Vijayalakshmi NR, Hypoglycaemic effect of Coccinia indica: mechanism of action. Planta Med $1993 ; 59: 330-332$

18. Augusti KT, Daniel RS, Cherian S, Sheela CG, Nair CR, Effect of leucopelargonin derivative from Ficus bengalensis Linn. on diabetic dogs. Indian J Med Res. 1994; 99:82-86.

19. Yang M, Wang BX, Jin YL, Wang Y, Cui ZY, [Effects of ginseng polysaccharides on reducing blood glucose and liver glycogen]. Zhongguo Yao Li Xue Bao 1990; 11:520-524.

20. Rao BK, Kesavulu MM, Giri R, Appa Rao C, Antidiabetic and hypolipidemic effects of Momordica cymbalaria Hook. fruit powder in alloxan-diabetic rats. J Ethnopharmacol 1999; 67:103-109.

21. Chattopadhyay RR, Hypoglycemic effect of Ocimum sanctum leaf extract in normal and streptozotocin diabetic rats. Indian $\mathbf{J}$ Exp Biol 1993; 31:891-893.

22. Kumar A, Iiavarasan R, Jayachadran T, Deecaraman M, Kumar RM, et al., Anti-inflammatory activity of Syzygiumcumini seed. Afr J Biotechnol 2008; 7:941-943.

23. Hannan JMA, Ali L, Rokeya B, Khaleque J, Akhter M, et al. Soluble dietary fibre fraction of Trigonellafoemum-gracecum (fenugreek) seed improves glucose homeostasis in animal models of Type 1 and Type 2 diabetes by delaying carbohydrate digestion and absorption and enhancing insulin action. Br J Nutr 2007; 97:514-521.

24. Padmanabha Rao A, Jamil K, Preclinical Evaluation Of Polyherbal Formulations: Hypoglycemic Activity In Rats International Journal of Ayurvedic And Herbal Medicine 2012; 2(2):218:228

\begin{tabular}{|l|l|l|}
\hline Phytoconstituents & Plant & Part \\
\hline Alkaloids & \multicolumn{2}{l|}{} \\
\hline Berberine & Berberis sp. Tinospora cardifolia & Bark \\
\hline Casurine 6-o-glucoside & Syzgium malacene & Leaves and stem \\
\hline Cathaarnthine,Vindoline,vindolamine & Catharanthus roseus & Fruit \\
\hline Calystigine b-2 & Nicandra physalades & \\
\hline Cryptolepine & Cryptolepis sanguinolenta & \\
\hline Harmane Nor harmane & Tribulus teresris & Seeds, fruit and bark \\
\hline Jambosine & Syzgium cumuni & \\
\hline Jatrorhizine, magnoflorine plamatine & Tinospora cordifolia & Roots \\
\hline $\begin{array}{l}\text { Javaberine A, javaberine hexa acetate, Javaberine B } \\
\text { hexa acetate, }\end{array}$ & Talinun paniculatum & Seeds \\
\hline Lepidine and semi lepidine & Lepidium sativum & \\
\hline
\end{tabular}




\begin{tabular}{|c|c|c|}
\hline Luparine & Lupinus perennis & Leaves \\
\hline Mahanimbine & Murraya & branches \\
\hline \multicolumn{3}{|l|}{ Piperum bellactum A } \\
\hline \multicolumn{3}{|l|}{ Radicamines $\mathrm{A}$ and $\mathrm{B}$} \\
\hline Swechirin & Swertia Chirayta & \\
\hline Tecomine & Tecoma stans & \\
\hline trigoneline & Trigonella foenum-graceum & Seed \\
\hline 1-deoxynoiirimycin & Morus alba & Leaves, bark \\
\hline \multicolumn{3}{|l|}{ Glycoside } \\
\hline Kalopanax & Kalapanax pictus & Stem, bark \\
\hline Jamboline, or antimellin & Syzgium cumini & Seed \\
\hline Myrciacitrins I and II myrciaphenone A and B & Myrcia multiflora & Leaves \\
\hline neomyrtillin & Vaccinium myrtillus & Leaves \\
\hline Perargonidine 3-0-1 rhamnoside & Ficus bengalensis & Bark \\
\hline Pseudoprotinosaponin AIII and protinosaponin AIII & Anemarhena ashodeloides & Rhizome \\
\hline $\begin{array}{l}\text { Vitexine, isovitexine and isorhamnetine } 3 \text {-o-d } \\
\text { rutinoside }\end{array}$ & Microcas paniculata & Leaves \\
\hline \multicolumn{3}{|l|}{ Flavonoids } \\
\hline Bengalenoside & Ficus benghalensis & Stem bark \\
\hline \multicolumn{3}{|l|}{ Cynidine -3-galactoside } \\
\hline Epigallocatechine gallate & Camellia sinensis & Leaves \\
\hline 3-o - galloylpicatechine & Bergenia ciliata & \\
\hline Genistein & Glycine spp. & Soya beans \\
\hline Hesperidin, naringin & Citrus spp. & \\
\hline prunin & Amygdalus daviana & stem \\
\hline Kaempferol & Jindai soybean & Leaves \\
\hline Kolaviron & Garcinia kola & \\
\hline Leucodelphinidin & Ficus bengalnesis & Bark \\
\hline Mngiferin & Anemarrhena aspodeloides & Rhizomes \\
\hline Marsuspin, pterostilbene & Pterocarpus marsupium & Heartwood \\
\hline Quercetin & Chamaecostus cuspdtus & \\
\hline Rutin & 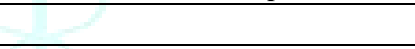 & \\
\hline Shaminin & Bombax ceiba & Leaves \\
\hline \multicolumn{3}{|l|}{ Terpenoids and steroids } \\
\hline Alpha amyrin acetate & Ficus racemosa & Fruit \\
\hline Andrographolide & Andrographis paniculata & Leaves \\
\hline Acetoxy -16-b-hydroxybetulinic acid & Zanthoxylum gilletii & Stem bark \\
\hline Bassic acid & Bumelia sartorum & Root bark \\
\hline Charantin & Momordica charantia & Seeds, fruits \\
\hline Christinin A & Zizyphus spina-christi & Leaves \\
\hline Colosolic acid, maslinic acid & Lagerstroemia speciosa & Leaves \\
\hline Corosolic acid & Vitex spp. & Leaves \\
\hline Elatosides E & Aralia elata & Root cortex \\
\hline Escins-IIA and IIB & Aesculus hippocastanum & Seeds \\
\hline Forskolin & Coleus forskohlii & \\
\hline Ginsenosides & Panax species & Rhizomes \\
\hline Gymnemic acid IV & Gymnema sylvestre & Leaves \\
\hline Momordin ic & Kochia scoparia & Fruit \\
\hline b-sitosterol & Azadirachta indica & \\
\hline Senegin derivatives & Polygala senega & \\
\hline \multicolumn{3}{|l|}{ Polysaccharides } \\
\hline Aconitans A-D & Aconitum carmichaeli & Roots \\
\hline Atractans A & Atractylodes japonica & Rhizomes \\
\hline Ganoderans A and B & Ganoderma lucidum & Fruit bodies \\
\hline Galactomannan gum & $\begin{array}{l}\text { Cyamopsis tetragonolobus } \\
\text { Amorphophallus konjac }\end{array}$ & Seeds Tubers \\
\hline \multicolumn{3}{|l|}{ Miscellaneous } \\
\hline Allicin & Allium sativum Allium cepa & Bulbs \\
\hline Bellidifolin & Swertia japonica & \\
\hline Bakuchiol & Otholobium pubescens & \\
\hline
\end{tabular}




\begin{tabular}{|l|l|l|}
\hline Curcuminoids & Curcuma longa & Rhizomes \\
\hline Ellagitannins & Terminalia chebula & Fruits \\
\hline Ferulic acid & Curcuma longa & Leaves seeds \\
\hline Ginseng polypeptides & Panax ginseng & Roots \\
\hline 4-hydroxyisoleucine & Trigonella foenum-graecum & Seeds \\
\hline Kotalanol & Salacia reticulate & \\
\hline Masoprocol & Larrea tridentate & \\
\hline Paeoniflorin, 8-debenzoylpaeoniflorin & Paeonia lactiflora & Root \\
\hline
\end{tabular}

